\title{
La Generación poética de los años 20 en España*
}

\author{
POR JORGE GUILIÉN
}

Algunos amigos han solicitado de este conferenciante algunas declaraciones autocríticas más o menos relacionadas con el asunto considerado en esta serie de conferencias. ¿Sería discreto complacer a tan buenos amigos? No sería discreto. Tales situaciones -embarazosas-pueden resolverse mediante una conciliación. Para evitar el yo protagonista, "le moi haissable", hablemos de "nosotros" : el grupo de poetas que, con los rasgos de una generación, vivió y escribió en España entre 1920 y 1936. Es la generación de Federico García Lorca, su representante más célebre. Picasso y Lorca ersumos caridaluces modernos con Falla y Juan Ramón Jiménez- son los dos españoles contemporáneos más visibles en el horizonte de la historia occidental. Son ellos sin duda los más geniales. Picasso encontró en París el ambiente y el mercado que necesitaba su pintura. Lorca no tuvo que emigrar. En la España de su tiempo florecía la literatura con esplendor, y entre sus coetáneos había figuras de primer orden.

Este primer tercio del siglo $\mathrm{XX}$, fecundo en grandes prosistas, ha sido también muy rico en poetas. Tras los mayores -Unamuno, Antonio Machado, Juan Ramón Jiménez, muy presentes a la vez que Gabriel Miró y Ramón Gómez de la Serna- surgen varios líricos que muy pronto forman un conjunto homogéneo. Homogéneo, sí, el conjunto -pero constituído por personalidades muy distintas. La idea de generación estaba ya en el aire. En-

* Conferencia leída en el Salón de Grados de la Facultad de Letras, el jueves 7 de Diciembre de 1961. 
tonces apareció, y aquí reaparece ahora como una realidad conocida empíricamente, $\mathrm{y}$ de ningún modo por inducción a posteriori. Raras veces se habría manifestado una armonía histórica con tanta evidencia como durante el decenio del 20 entre los gustos y propósitos de aquellos jóvenes, cuyd vida intelectual se centraba en Madrid. Nadie obedecía, claro, al sistema lógicamente establecido, y por eso fatal, de algunos filósofos que registran sobre un papel la marcha de las generaciones a pasos e intervalos rigurosamente simétricos. Es paradójico que este determinismo malgré lui se proclame al amparo de la noción de vida, de existencia. Aquí se trata sólo de un saber experimental, de historia vivida, no estudiada. Hacia 1925 se hallaban más o menos relacionados ciertos poetas españoles. Si una generación agrupa a hombres nacidos durante un período de quince años, esta generación tendría su fecha capital en 1898: entonces nacen Federico García Lorca, Dámaso Alonso, Vicente Aleixandre. Mayores eran Pedro Salinas, Jorge Guillén, Gerardo Diego - del 91, del 93, del 96. Un año más joven que Lorca es Emilio Prados, del 99. A este siglo pertenecen Luis Cernuda, de 1902, Rafael Alberti, del año $3, y$ el benjamín Manuel Altolaguirre, del año 5. De Salinas a Altolaguirre se extienden los tres lustros de rigor - de rigor teórico. Sería superfluo añadir más fechas. También cumplen con su deber cronológico Antonio Espina, Pedro Garfias, Adriano del Valle, Fuam Larrea, Juan Chabás, Juan José Domenchina, José María Hinojosa, Ernestina de Champourcin, José María Quiroga Pla, los de la revistaCMeseta de Valladolid, los de Mediodía de Sevilla...

Esta enumeración es injustamente incompleta, y sólo se cita ahora a los líricos en verso, y no a quienes los son en narraciones y ensayos. "Literatura" viene a significar entonces "lirismo". La mayoría de estos poetas es andaluza. Castilla y Andalucía han sido las principales fuentes de la poesía española. En el pasado Castilla sobre todo; en el presente, y con gran preponderancia, Andalucía. Todos, castellanos y andalúces, resultan sin habérselo propuesto, muy contemporáneos de sus contemporáneos en Europa, en América. Aquellos líricos se sienten a tono con la atmósfera general de los años 20, aunque posean acentos que sólo responden $a$ una tradición española.

Ya ha sido señalada esa primordial característica. Una generación tan "innovadora" no necesitó negar a los antepasados 
remotos o próximos para afirmarse. "Lo primero que hay que no. tar - dice Dámaso Alonso, actor y cronista- es que esa generación no se alza contra nada". Todo lo contrario: sus raíces se ahincan en un pretérito más y más profundo. Ya los escritores del 98 habían renovado el interés por algunas obras y algunos autores que ellos creían "primitivos": el Poema del Cid, Gonzalo de Berceo, el Arcipreste de Hita. Ahora se airea todo el Siglo de Oro lírico, y no solamente a Góngora. Entre Garcilaso y Quevedo reaparecen los admirables segundones: 'Figueroa, Aldana, Medina Medinilla, Medrano, Espinosa, Villamediana, Soto de Rojas... Y si se vindica al gran Don Luis cordobés, se da valor actual a Gil Vicente, a Fray Luis de León, a San Juan de la Cruz, a Lope, a Quevedo. Estos actos de buena memoria no implican sobre todo discriminación de erudito, aunque no sean ajenos a los deleites de la erudición tales poetas, hasia los que no son profesores. (Lo son Pedro Salinas, Jorge Guillén, Gerado Diego, Dámaso Alonso). Pero también Lorca escribe sóbre Góngora, y es él quien pone al granadino Soto de Rojas ante nuestros ojos. ¿Y quién con más capacidad de asimilación y más reminiscencias de cultura que el nada universitario Rafael Alberti? Tantos retornos a la poesía antigua son obra de poetas en cuanto poetas. Y como todos ellos propugnan la expresión más rigurosa, los antiguos y modernos textos son admirados sifavorecen la autenticidad de la poesía. Por eso también se defiende Y se estudia a Bécquer, exento de complicaciones formales y tan puro fenómeno inspirado. En lugar aparte se coloca a Juan Ramón Jiménez - aunque Antonio Machado ocupe el mismo nivel de eminencia-porque Juan Ramón es gran ejemplo de fervorosa voluntad literaria. Por último, los más leídos y amados poetas extranjeros son los franceses, desde Baudelaire hasta los superrealistas.

Por tantas vías y sin restricciones dogmáticas de escuela -no
hay escuela ni dogma- aquellos muchachos buscan una poesía
que es al mismo tiempo arte en todo su rigor de arte y creación
en lodo su genuino empuje. Arte de la poesía, y por lo tanto, nin-
guna simple efusión - ni al modo del siglo pasado ni con violen-
cia de informe chorro subconsciente. No hay charlatanería más ya-
na que la del subconsciente abandonado a su trivialidad. En Es- 
paña nunca se contentó nadie con el "documento" superrealista: Arte de la poesía, pero ningún huero formalismo. Claro que el semi-ignorante de hoy llama - con porte de fiscal- formalismo a la plenitud de una forma bien trabajada, es decir, cuidadosamente ajustada a su contenido. Son muy variados y muy numerosos los metros, las estrofas, las modulaciones, los ritmos que entonces se emplean. Forzoso es apelar al término de maestría. Algunos lo sustituyen por el de virtuosismo. En el "virtuosismo" hay "virtud", pero mordida, rebajada. Sin embargo, "'virtud" resiste bajo la denuncia. Aquella maestría fue lograda en algunas ocasiones con precoz rapidez. Así, Rafael Alberti, casi casi maestro de nacimiento. No podría oponerse el dominio de algunos a la espontaneidad de otros, porque estos otros - Lorca, por ejemploeran tan "sabios" como sus compañeros profesores. Poesía como arte de la poesía: forma de una encarnación. Podríamos escribir esta palabra con mayúscula: misterio de la Encarnación. El espíritu llega a ser forma encarnada misteriosamente, con algo irreductible al intelecto, en esta bodas que fundan idea y música.

"Idea" es aquí signo de realidad en estado de sentimiento. La realidad está representada, pero no descrita según un parecido inmediato. Realidad, no realismo. $Y$ el sentimiento, sin el cual no hay poesía, no ha menester de gesticulación. Sentimiento, no sentimentalismo, que fuelcondenado entonces como la peor de las obscenidades. Esta mesura en la manifestación de las emociones guarda su vehemencia, más aún, redobla su intensidad. Pero hay oídos sordos para quienes tales armonías se confunden casi con el silencio. De ahí que algunos de estos poetas fuesen juzgados fríos, aunque se consagraran a declarar su entusiasmo por el mundo, su adhesión a la vida, su amor al amor. El cambio en los medios expresivos no permite ver $a$ ciertos lectores -que terminarán, después de años de aprendizaje, por entender y sentir un cálido poema erótico como tal poeta erótico. Esos lectores añadían, al reproche de la frialdad, el de la abstracción. IEran tan intelectuales estos poetas! En efecto, muchas abstracciones se entrelazaban con los componentes más plásticos en algunos de aquellos poemas. Esto ha ocurrido siempre, y no hay lenguaje sin combinación de lo intelectual con lo concreto. De todos modos, jamás soñó nadie con una poesía de la pura inteligencia. Tenía razón Antonio Machado en sostener que "el intelecto no canta". Los poetas incriminados no pretendieron nunca prescindir del ma- 
nantial en que nace la lírica eliminando el corazón. El gran don Antonio, justo de pensamiento, disparaba sin dar en ningún blanco. Aquellos poetas no se habian "saltado" nada - nada esencial: eran poetas. (Por otra parte, Machado se acercaba al borde de la lírica en aquellos aforismos versificados tan próximos a las disertaciones del profesor Juan de Mairena).

En suma, los poetas de los años 20 eran, si no fríos y sólo abstractos, por lo menos difíciles, herméticos, oscuros. Difíciles, sí, como muchos otros poetas. ¿Herméticos? Esta palabra - con la que se suele designar a sus contemporáneos italianos- no prevaleció en España. ¿Oscuros? Es término anticuado. A la larga fue disipándose casi toda la oscuridad, más tolerada en los autores de gram delirio con discurso muy libre - como Vicente Aleixandre que en los de composición más lógicamente apretada, como Jorge Guillén. Sería imposible, además, dividir a estos poetas en dos grupos: los fáciles y los arduos - división que disgustaba a Lorca. Verdad es que Poeta en Nueva York no parece más sencillo que $L a$ voz a ti debida o Cántico. El lenguaje que presume de ser muy racional -el de la política verbi gratia- ¿no encierra ya un semillero de confugiones? Será más fértil en confusiones el lenguaje de quien acude, refiriéndose a su vida más profunda, a la ambigüedad de las imágenes. Aquellos poetas hablaban por imágenes. Y on este punto2-la prepotencia metafóricase reunen todos los hilos rel nombre dimericano deo"imagists" podría aplicarse a cuantos escritores de alguna imaginación escribían acá o allá por los años 20. Góngora, Rimbaud, Mallarmé, y más tarde otras figuras - de Hopkins a Eluard-son estímulos que conducen a refinar y multiplicar las imágenes. De ese modo - como se dice en el Romancero gitano- "la imaginación se quema". Este cultivo de la imagen es el más común entre los muy diversos caracteres que juntan y separan a los poetas de aquellos años, y no sólo a los españoles. "Imagen" se denomina una obra temprana de Gerardo Diego. El cultivo se convierte en un culto supersticioso: los más extremos reducen la poesía a una secuencia de 1 mágenes entre las que se han suprimido las transiciones del discurso. No quedan más que frases sueltas: última condensación de la actividad literaria. Cualquier enlace en función lógica y gramatical es sospechoso de inercia poética. Las imágenes mismas tampoco se someten a relaciones observadas. Supervivientes a pesar de todo, la realidad no será reduplicada en copias sino re- 
creada de manera libérrima. Esa libertad expresará más el mundo interior del hombre - "el subconsciente" se le llamaba a menudo- que las realidades según las categorías de la razón. Por supuesto, los grados de equivalencia entre lo real y lo imaginativo varía mucho. Ciertos escritores quieren alzarse a una segunda realidad, independiente de la primera realidad común: autonomía de la imagen.

\section{III}

El poeta siente en su plenitud etimológica el vocablo "poesía". (Pero esta "creación" será, quiéralo o no, segunda respecto a la del primer creador del Génesis. Todos los poetas son "poetes du dimanche", del domingo que sigue al sábado en que descansó Jehová). Hay que recoger, para evocar la atmósfera de aquellos años, esta voluntad de poesía como creación, de poema como quintaesenciado mundo. Grave o alegremente, las obras de aquel tiempo apuntan a una meta esencial, Y son todo excepto el deporte sin trascendencia que algunos comentaristas vieron en aquella pululación de imágenes. Nada más serio, además, que jugar en serio, y es indudable que en 1925, en 1930, en 1935 se jugó a la mejor poesía asequible con toda ingenuidad. Aquellos poetas no se creían obligados a ejercer ningún sacerdocio, y ninguna pompa religiosa, política, social acartonaba sus gestos. Gestos de espectáculo no' habica. Sí habia propósitos de 'rigurosa poesía como creación. ¿Y si el poema fuese todo él poético? Esta ambición flotaba difusa en la brisa de aquellas horas. Era preciso identificar lo más posible poesía y poema. Sería falso imaginarse una doctrina organizada. Abundaban, eso sí, las conversaciones -y los monólogos- sobre los aspectos generales de aquel menester o mester. "Ismos" no hubo más que dos, después del ultraísmo preliminar: el creacionismo, cuyo Alá era Vicente Huidobro, admirable poeta chileno, y cuyos Mahomas eran Juan Larrea y Gerardo Diego, y el superrealismo, que no llegó a cuajar en capilla, y fue más bien una invitación a la libertad de las imaginaciones. Por unos o por otros caminos se aspiró al poema que fuese palabra por palabra, imagen a imagen, intensamente poético.

¿"Poesía pura"? Aquella idea platónica no admitía realización en cuerpo concreto. Entre nosotros nadie soñó con tal pureza, nadie la deseó, ni siquiera el autor de Cántico, libro que negati- 
vamente se define como un anti-Charmes. Valéry, leído y releído con gran devoción por el poeta castellano, era un modelo de ejemplar altura en el asunto y de ejemplar rigor en el estilo - a la luz de una conciencia poética. Acorde al linaje de Poe, Valéry no creía o creía apenas en la inspiración- con la que siempre contaban estos poetas españoles: musa para unos, ángel para otros, duende para Lorca. Esos nombres diurnos o nocturnos, casi celestes o casi infernales, designaban para Lorca el poder que actúa en los poetas - sin necesidad de trance místico. Poder ajeno a la razón y a la voluntad, proveedor de esos profundos elementos imprevistos que son la gracia del poema. Gracia, encanto, hechizo, el no sé qué -y no "charme" fabricado. A Valéry le gustaba con placer un poco perverso discurrir sobre "la fabricación de la poesía". Esas palabras habrían sonado en los oídos de aquellos españoles como lo que son: como una blasfemia. "Crear", término del orgullo, "componer", sobrio término profesional, no implican fabricación. Valéry fue ante todo un poeta inspirado. Quien lo es tiene siempre cosas que decir. T. S. Eliot, gran crítico ya en los años 20, lo ha dilucidado más tarde con su habitual sensatez: "Poets have other interests beside poetry -otherwise their poetry would be very empty: they are poets because their dominant interest has been in turning their experience and their thought ... into poetry". El formalismo hueco o casi hueco es un monstruo inventado por el lector incompetente o sólo se aplica a escritores incompetentes.

"Jorge Puccinelli Converso"

Si hay poesía, tendrá que ser humana. ¿Y cómo podría no serlo? Poesía inhumana o sobrehumana quizás ha existido. Pero un poema "deshumano" constituye una imposibilidad física y metafísica, y la fórmula "deshumanización del arte", acuñada por nuestro gran pensador Ortega y Gasset, sonó equívoca. "Deshumanización" es concepto inadmisible, y los poetas de los años 20 podrían haberse querellado ante los Tribunales de Justicia a causa de los daños y perjuicios que el uso y abuso de aquel novedodo vocablo les infirió como supuesta clave para interpretar aquella poesía. Clave o llave que no abría ninguna obra. Habiendo analizado y reflejado nuestro tiempo con tanta profundidad, no convenció esta vez Ortega, y eso que se hallaba tan sumergido en aquel ambiente de artes, letras, filosofías. No ha de olvidarse -porque en el olvido habría ingratitud- la ayuda generosa que Ortega prestó a los jóvenes desde su Revista de Occidente. 
En una de sus colecciones - Nova Novarum - fueron publicados cuatro libros: Romancero gitano, Cántico, Seguro Azar, Cal y Canto. Es placentero -y melancólico- recordar aquellos años en que la Revista de Occidente, según nuestro amigo Henry Peyre, formaba con La Nouvelle Revue Francaise y The Criterion la suma trinidad de revistas europeas. ¡Y precisamente fue el gran Ortega quien forjó aquella palabra! No era justo ni referido a las construcciones abstractas del cubismo. ¿Quién sino hombres con muchos refinamientos humanos -Juan Gris, Picasso, Braquepintaban aquellas naturalezas muertas nada muertas? Se concibe, sí, una pintura no figurativa. Pero la palabra es signo y comunicación: signo de una idea, comunicación de un estado -como repite Vicente Aleixandre. Otra cosa habría sido hablar de antisentimentalismo, de antirrealismo.

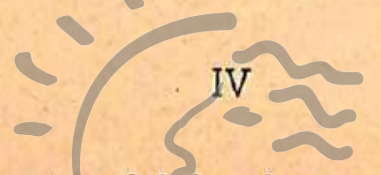

Los grandes asuntos del hombre -amor, universo, destino, muerte- llenan las obras líricas y drámaticas de esta generación. (Sólo un gran tema no abunda: el religioso). Cierto que los materiales brutos se presentan recreados en creación, transformados en forma, encarnados en carne verbal. Cierto que esa metamorfosis evita la grandilocuencia y sel complace em la sobriedad y en la mesura. El idioma español posee el vocablo "efectismo". Pues el efectismo es lo que se prohiben estos poetas. Efectista no fue la generación en que descollaba un poeta trágico, el único grande entre nosotros después de Calderón. El "duende" de Lorca nada tenía que ver con la insistencia gesticulante. A pesar de todo, algunos jóvenes españoles de hoy - y con qué nostalgia se dice aquí "jóvenes"I- caen en la ingenuidad de creer que ellos han descubierto la poesía humana. Valga ahora la exclamación popular ISanta Lucía proteja su perspicacial Ahí está la poesía de aquel decenio; léase o reléase con la actual perspectiva, y se verá si "deshumanización" ○ "asepsia" sirven para entender aquellas páginas. Verdad es que "asepsia" vagaba en el aire más vago de entonces. Pero pertenecía al léxico superficial, y ninguna presión ejercía durante la etapa creadora.

Aquí no se pretende reanimar sino ese aire común que respiran algunos amigos hasta en sus soledades, y no sólo en cafés, en tertulias. No hay programa, no hay manifiesto con agresión y 
defensa. Hay diálogos, cartas, comidas, paseos, amistad bajo la luz de Madrid, ciudad deliciosísima, aún Corte con augurios de República, donde tanto ingenio se despilfarra y tantas horas pierden $\longrightarrow$ parecen perder- aquellos laboriosos intelectuales y artistas que trabajan por la cultura de su país. Cultura con sentido liberal. Estos poetas, procedentes de una burguesía nada ociosa, si no actúan como militantes en política, no la desconocen, orientados hacia una futura España más abierta. Algunos, torpes, han llamado "generación de la Dictadura" a la de Salinas y sus amigos, cuando ninguno de ellos participó de ningún modo en el régimen de Primo de Rivera, tan anticuadamente dictatorial que no obligó a concesiones en el comportamiento ni en los escritos de esa generación. Escritores de dictadura surgen más tarde. Entre el 20 y el 36 había tiempo libre: libre para que se cumpliese cada destino individual.

Aquellos poetas, muy bien avenidos, eran muy diferentes. Cada uno tenía su voz. Antonio Machado se paraba a distinguir las voces de los ecos. Allí no sonaban más que voces propias, y así lo reconoció el gran don Antonio que respetaba a estos poetas, aunque tal vez no viese claras algunas de sus obras. Poetas afortunados: en seguida fueron acogidos. $\AA$ esta rapidez en el acogimiento, debida a sabe Dios cuántas circunstancias, contribuyó la definición tan evidente de cada figura. Hostilidad de público - un público poco extenso- no había. Erán poetas de los llamados "de vanguardia" cr gtra palabrejal de caquel tiempo. Aquella metáfora militar no convenía a quienes no luchaban con nadie en ningún frente. Tampoco se proponían una meta detonante. La meta, difícil siempre, era esa expresión justa que corresponde a eso que se está queriendo manifestar. $Y$ así, buscando su nota genuina, resultaron modernos, acordes a su épocas. Nunca falta lector 0 espectador que sospeche malicia, truco, insinceridad, ansia de fama en pintores o escritores de veras nuevos - sin advertir que están jugándose la vida a cada pincelada, a cada rasgo.

\section{V}

¿Cómo se expresa esta generación, cuál es su palabra? ¿Es imposible reducir a unidad el lenguaje $\rightarrow$ los lenguajes - de escritores tan diversos? Joaquín González Muela ha intentado formular esos estilos en exacta síntesis. ¿Qué tienen de análogo 
Salinas y Altolaguirre, Prado y Cernuda? Alrededor de una mesa fraternizan, se comprenden, hablan el mismo idioma: el de su generación. A la hora de la verdad, frente a la página blanca, cada uno va a revelarse con pluma distinta. Esta pluma se mueve desde los artificios de la métrica tradicional hasta las irregularidades del versículo. No se ha roto con la tradición, y las novedades de Rubén Darío y de sus continuadores van a ser ampliadas por estos poetas que, si ponen sordina en las innovaciones, no se circunscriben a las formas empleadas por los maestros remotos o inmediatos. La ruptura con el pasado fue mucho mayor en las generaciones contemporáneas de otros países. A la herencia española no se renunció, y esta herencia no coartó el espíritu original. ¿Qué poeta de entonces, francés, italiano, sobre todo italiano, se habría atrevido a escribir sin ruborizarse un soneto? Para aquellos españoles el soneto podía ser escrito en un acto de libertad, conforme a su "real gana" poética. Hasta un Salinas, un Aleixandre compusieron algún soneto, y no por capricho de "virtuoso": así convenía a su impulso creador. Por eso es tan rico el repertorio formai de esta generación, que rehuyó el voto de pobreza exigido por la modernidad a muchos de sus secuaces. Hay una censura que jamás se ha dirigido a estos poetas: que escriban mal. Sí se les ha reprochado que escriban demasiado bien. Esta objeción es, en realidad un elogio as-acompañado de zancadilla. En suma, ni en el caso de Lorca la genialidad autorizaba una escritura genialmente informe, un cabandono a los poderes oscuros. La más ligera canción aparecía redactada con los primores del arte, y los versículos de La destrucción o el amor, de $\mathrm{Hi}$ jos de la ira, años después estaban con toda puntualidad respirados. Las maneras más divergentes se sucedían, según variaba el mismo autor -así Gerardo Diego- y hasta se contraponían en la misma obra como en su Fábula de Equis y Zeda.

Todo nombre unificador de un período histórico es inventado o aceptado por la posteridad. Si a Poliziano le habría sorprendido el mote de "renacentista", a Verlaine - lo sabemos- no le agradaba el título de "simbolista". Cierto que desde el siglo XIX han pululado las teorías y los "ismos". No en España. Por excepción hubo un ultraísmo; el creacionismo - como el modernismoprocedía de América. El cubismo -parcialmente de origen español, merced a Picasso, a Juan Gris- se elaboró en Francia. ¿Cómo designar los años tan revueltos y tan fecundos entre las 
dos guerras mundiales? No hay etiqueta verosímil, sobre todo para los actores de aquellas aventuras. "Aire de época" no significa "estilo de grupo", de un grupo determinado. Una generación posee éstas o las otras aficiones, pero no desarrolla una línea de escuela, de lenguaje. Al empleo de su lenguaje se lanzaron aquellos poetas sin desconfiar de su eficacia. Dice Wladimir. Weidlé: "En España los poetas no están obligados a desconfiar excesivamente de la lengua de cada día, pues esta lengua está mucho menos despoetizada que en Francia o en Inglaterra". El castellano es, además, un idioma copioso, flexible, y más que nunca en los escritos de la generación precedente. ¿Qué ocurrió después?

La poesía no requiere ningún especial lenguaje poético. Ninguna palabra está de antemano excluída; cualquier giro puede configurar la frase. Todo depende, en resumen, del contexto. Sólo importa la situación de cada componente dentro del conjunto, y este valor funcional es el decisivo. La palabra 'rosa" no es más poética que la palabra "política". Por supuesto, "rosa" huele mejor que "política": simple diferencia de calidades reales para el olfato. (Dice Shakespeare, o más bien Julieta a Romeo: "...a rose - By any other name would smell as swet"). Belleza no es poesía, aunque sí muchas veces su aliada. De ahí que haya más versos en que se acomode "rosa" que "política". A priori, fuera de la página, no puede adscribirse índole poética a un nombre, a un adjetivo, a un gerundiogeEs probable que I"administración" no haya gozado aún de resonancia lírica. Pero mañana, mañana por la mañana podría ser proferido poéticamente - con reverencia, con ternura, con ira, con desdén- "AAdministración!" Bastaría el uso poético, porque sólo es poético el uso, o sea, la acción efectiva de la palabra dentro del poema: único organismo real. No hay más que lenguaje de poema: palabras situadas en un conjunto. Cada autor siente sus preferencias, sus aversiones y determina sus límites - según cierto nivel. El nivel del poema varía; varía la distancia entre el lenguaje ordinario y este nuevo lenguaje, entre el habla coloquial y esta oración de mayor o menor canto. A cierta altura se justifican las inflexiones elocuentes. Nada más natural, a otra luz que las inflexiones prosaicas, asi ya no prosaicas. En conclusión, el texto poético tiene su clave como el texto musical. Absurdo sería trasferir notas de La realidad y el deseo a Soledades juntas, a Jardín cerrado. Lenguaje poético, no. Pero sí lenguaje de poema, modulado en gradaciones de intensi- 
dad y nunca puro. ¿Qué sería esa pureza, mero fantasma concebido por abstracción? La poesía existe atravesando, iluminando toda suerte de materiales brutos. $Y$ esos materiales exigen sus nombres a diversos niveles de recreacción. Sólo en esta necesidad de recreación coincide el lenquaje de estos poetas inspirados, libres, rigurosos.

Sabe Dios cuánto habría durado aquella comunidad de amigos, si una catástrofe no le hubiera puesto un brusco fin de drama $\circ$ tragedia. Tragedia absoluta fue el asesinato de Federico García Lorca, criatura absolutamente genial. Tragedia con sus traidores responsables y con su coro: toda España, el mundo entero. También nos falta el mayor de aquel grupo, Pedro Salinas, fallecido prematuramente, en plena madurez de producción. El final de Cántico le llama "amigo perfecto" y así lo fue siempre con una continua generosidad inextinguible*. Nuestra generación trabajó como grupo entre 1920 y 1936. Aquellas reuniones en Madrid terminaron aquel año nefasto de la guerra, preludio de la segunda guerra mundial. CPero no podría denominarse "lost generation" a la de aquellos poetas; a pesar de tantas vicisitudes, han seguido adelante. Pedro Salinas se creciô mucho en América, y nunca fue tan fecundo como en el decenio del 40. Gerardo Diego, Vicente Aleixandre, Dámaso Alonso han ampliado y ahondado su labor juvenil. Los demás, en emigración forzosa o voluntaria, han sido fieles a sus vocaciones. Más tarde se justipreciará cómo el destierro ha influído en estos hombres de la "España peregrina". Superior a tantas crisis, España se mantiene y se mantendrá en pie. Recordaba el profesor Fritz Shalk que Cántico afirma esa fe contra viento y marea.

Que los muertos entierren a sus muertos,

Jamás a la esperanza.

- A todos no ha conmovido la muerte de Manuel Altolaguirre en azar de carretera. 


\section{LIBROS POETICOS ESENCIALES DE LA GENERACION TRATADA}

Poeta en Nueva York. F. G. L.

Romancedo Gitano. F. G. L.

La voz a ti debida. P. S.

Cántico. J. G.

Seguro Azar. P. S.

Cal y Canto. R. Alberti.

La destrucción o el amor. V. Aleixandre.

Hijos de la ira. D. Alonso.

La realidad $y^{*}$ el deseo. L. Cernuda.

Soledades juntas. M. Altolaguirre.

Jardin Cerrado. E. Prados.

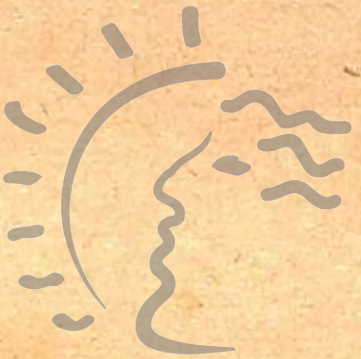

Biblioteca de Letras "Jorge Puccinelli Converso" 